\title{
Light Physical Activity is Associated with Quality of Life after Colorectal Cancer
}

Citation for published version (APA):

van Roekel, E. H., Bours, M. J. L., Breedveld-Peters, J. J. L., Meijer, K., Kant, IJ., van den Brandt, P. A., Sanduleanu, S., Beets, G. L., \& Weijenberg, M. P. (2015). Light Physical Activity is Associated with Quality of Life after Colorectal Cancer. Medicine and Science in Sports and Exercise, 47(12), 2493-2503. https://doi.org/10.1249/mss.0000000000000698

Document status and date:

Published: 01/01/2015

DOI:

10.1249/mss.0000000000000698

Document Version:

Publisher's PDF, also known as Version of record

Document license:

Taverne

Please check the document version of this publication:

- A submitted manuscript is the version of the article upon submission and before peer-review. There can be important differences between the submitted version and the official published version of record.

People interested in the research are advised to contact the author for the final version of the publication, or visit the DOI to the publisher's website.

- The final author version and the galley proof are versions of the publication after peer review.

- The final published version features the final layout of the paper including the volume, issue and page numbers.

Link to publication

\footnotetext{
General rights rights.

- You may freely distribute the URL identifying the publication in the public portal. please follow below link for the End User Agreement:

www.umlib.nl/taverne-license

Take down policy

If you believe that this document breaches copyright please contact us at:

repository@maastrichtuniversity.nl

providing details and we will investigate your claim.
}

Copyright and moral rights for the publications made accessible in the public portal are retained by the authors and/or other copyright owners and it is a condition of accessing publications that users recognise and abide by the legal requirements associated with these

- Users may download and print one copy of any publication from the public portal for the purpose of private study or research.

- You may not further distribute the material or use it for any profit-making activity or commercial gain

If the publication is distributed under the terms of Article $25 \mathrm{fa}$ of the Dutch Copyright Act, indicated by the "Taverne" license above, 


\title{
Light Physical Activity Is Associated with Quality of Life after Colorectal Cancer
}

\author{
ELINE H. VAN ROEKEL ${ }^{1}$, MARTIJN J. L. BOURS ${ }^{1}$, JOSÉ J. L. BREEDVELD-PETERS ${ }^{1}$, KENNETH MEIJER ${ }^{2}$, \\ IJMERT KANT $^{3}$, PIET A. VAN DEN BRANDT ${ }^{1}$, SILVIA SANDULEANU ${ }^{4}$, GEERARD L. BEETS ${ }^{5}$, \\ and MATTY P. WEIJENBERG ${ }^{1}$
}

${ }^{1}$ Department of Epidemiology, GROW School for Oncology and Developmental Biology, Maastricht University, Maastricht,
THE NETHERLANDS; ${ }^{2}$ Department of Human Movement Science, NUTRIM School for Nutrition, Toxicology and Metabolism,
Maastricht University, Maastricht, THE NETHERLANDS; ${ }^{3}$ Department of Epidemiology, CAPHRI School for Public Health
and Primary Care, Maastricht University, Maastricht, THE NETHERLANDS; ${ }^{4}$ Department of Internal Medicine, Division of
Gastroenterology and Hepatology, GROW School for Oncology and Developmental Biology, Maastricht University Medical
Center+, Maastricht, THE NETHERLANDS; ${ }^{5}$ Department of Surgery, GROW School for Oncology and Developmental Biology,
Maastricht University Medical Center+, Maastricht, THE NETHERLANDS

\section{ABSTRACT}

VAN ROEKEL, E. H., M. J. L. BOURS, J. J. L. BREEDVELD-PETERS, K. MEIJER, I. KANT, P. A. VAN DEN BRANDT, S. SANDULEANU, G. L. BEETS, and M. P. WEIJENBERG. Light Physical Activity Is Associated with Quality of Life after Colorectal Cancer. Med. Sci. Sports Exerc., Vol. 47, No. 12, pp. 2493-2503, 2015. Purpose: Emerging evidence suggests that light physical activity (LPA), besides moderate-to-vigorous physical activity (MVPA), may beneficially influence physical functioning of colorectal cancer survivors, but its relation with other health-related outcomes is unknown. We applied a biopsychosocial approach to investigate independent associations between self-reported LPA, MVPA, and multiple health-related quality of life (HRQoL) outcomes in 2- to 10-yr postdiagnosis colorectal cancer survivors. Methods: Stage I-III colorectal cancer survivors diagnosed between 2002 and 2010 at Maastricht University Medical Center+, the Netherlands, were included in a cross-sectional study $(n=151)$. Time spent in LPA and MVPA ( $\left.h \cdot \mathrm{wk}^{-1}\right)$, and HRQoL outcome scores (0-100 points) were assessed by validated questionnaires. Results: Median time spent in LPA and MVPA was 10.0 (interquartile range, 2.0-22.0) and $8.7 \mathrm{~h} \cdot \mathrm{wk}^{-1}(4.5-15.0)$, respectively. In multivariable linear regression models, both LPA and MVPA were significantly and independently associated with higher physical functioning (mean difference [MD] between highest and lowest quartile, 10.2; 95\% confidence interval [CI], 0.2-20.3; and 14.5; 5.1-23.9, respectively; both $P$-trend $<$ 0.05 ). In addition, LPA was significantly associated with higher role functioning (MD, 19.5; 95\% CI, 6.9-32.1; $P$-trend $<0.01)$ and lower disability (MD, $-9.9 ; 95 \% \mathrm{CI},-17.8$ to $-1.9 ; P$-trend $=0.02)$, independent from MVPA. Subgroup analyses showed that beneficial associations between LPA and HRQoL were mainly observed in women and participants with multiple comorbidities. Conclusions: Self-reported LPA, besides MVPA, was beneficially associated with multiple HRQoL outcomes in colorectal cancer survivors, especially in women and survivors with multiple comorbidities. Prospective studies are warranted to establish whether LPA is a suitable target for personalized lifestyle interventions to improve the HRQoL of colorectal cancer survivors. Key Words: SURVIVOR, LIFESTYLE, CROSS-SECTIONAL, HEALTH-RELATED QUALITY OF LIFE, BIOPSYCHOSOCIAL

$\mathrm{P}$ opulation ageing and increasing survival rates are leading to increased numbers of colorectal cancer survivors worldwide (22). In 2012, it was estimated that over 3.5 million people were living with a diagnosis of colorectal

Address for correspondence: Eline H. van Roekel, M.Sc., Department of Epidemiology, GROW School for Oncology and Developmental Biology, Maastricht University, P.O. Box 616, 6200 MD Maastricht, The Netherlands; E-mail: eline.vanroekel@maastrichtuniversity.nl.

Submitted for publication December 2014.

Accepted for publication April 2015.

Supplemental digital content is available for this article. Direct URL citations appear in the printed text and are provided in the HTML and PDF versions of this article on the journal's Web site (www.acsm-msse.org).

0195-9131/15/4712-2493/0

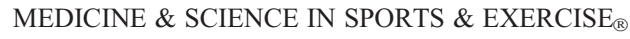

Copyright $(2015$ by the American College of Sports Medicine

DOI: $10.1249 /$ MSS.0000000000000698 cancer within the previous $5 \mathrm{yr}$ (6). Importantly, as a consequence of the cancer and/or its treatment, these survivors often experience a decline in multiple health-related quality of life (HRQoL) domains. Limitations in physical and social functioning and higher levels of fatigue and distress can persist up until $10 \mathrm{yr}$ after colorectal cancer diagnosis $(11,16)$.

A growing number of observational studies indicate that moderate-to-vigorous physical activity (MVPA), that is, activities with an intensity of $\geq 3$ metabolic equivalents (METs), such as brisk walking or cycling, is favorably associated with multiple HRQoL outcomes in colorectal cancer survivors $(9,15$, 17,20,23,36). Thus, current physical activity (PA) guidelines for cancer survivors recommend performing MVPA for at least $150 \mathrm{~min} \cdot \mathrm{wk}^{-1}(8,29)$. However, a large proportion of colorectal cancer survivors are unable to meet these recommendations because of a high prevalence of comorbidities and their relatively old age, which can limit their ability to 
exercise at a moderate or vigorous intensity (7). Therefore, more specific PA guidelines are needed for this population (8).

Emerging evidence suggests that light PA (LPA; 1.53 METs) might also confer health benefits in colorectal cancer survivors, independently from MVPA (4). LPA, including activities such as light household work and slow walking, might be a more suitable target than MVPA for improving the HRQoL of this population. To our knowledge, only two previous studies in colorectal cancer survivors have investigated associations of LPA with physical functioning $(4,17)$, but not with other HRQoL outcomes. HRQoL is a broad and multidimensional construct, which does not only have a physical dimension but also other domains of health and functioning, such as psychological and social functioning (34).

We have previously reported on the applicability of the International Classification of Functioning, Disability and Health (ICF) to systematically and comprehensively study lifestyle and HRQoL in colorectal cancer survivors, within the Energy for life after ColoRectal cancer (EnCoRe) study (38). The ICF was developed by the World Health Organization as a biopsychosocial classification of functioning of an individual or population of individuals in a certain health state (44). As a biopsychosocial classification, it integrates biomedical and psychosocial models of health and health care, and thus includes biological, individual and social perspectives on health and functioning (31). It describes functioning within the domains of body functions and structures (e.g., "mental functions" or "structures related to movement"), and activities and participation (e.g., "mobility" or "community, social and civic life"), in the context of environmental and personal factors acting as barriers or facilitators of functioning (e.g., medical treatment or sex) (18). Importantly, the ICF incorporates not only physical aspects of health but also qualitative features, such as psychological functioning and societal participation, and is therefore very useful for HRQoL studies (38). In addition, it enables identification of contextual factors influencing functioning, which is important for the development of personalized PA recommendations for colorectal cancer survivors $(24,38)$.

The purpose of this study was to investigate cross-sectional associations between self-reported LPA, MVPA, and multiple HRQoL outcomes in 2- to 10 -yr postdiagnosis colorectal cancer survivors using an ICF-based biopsychosocial approach. We hypothesized that both LPA and MVPA would be independently and beneficially associated with HRQoL outcomes in colorectal cancer survivors.

\section{METHODS}

Study design and participants. Methods of the EnCoRe study, including an ongoing prospective part and a cross-sectional part, have been described previously (38). For this paper, data were used from the cross-sectional part, which was conducted in 2- to 10-yr postdiagnosis stage I-III colorectal cancer survivors. Eligible subjects, that is, individuals diagnosed and treated between 2002 and 2010 at
Maastricht University Medical Center+, the Netherlands, were preselected via the Netherlands Cancer Registry (NCR; managed by Comprehensive Cancer Centre the Netherlands). Reasons for exclusion are shown in Figure 1. Participants were recruited between May 2012 and December 2013. The EnCoRe study has been approved by the Medical Ethics Committee of the Academic Hospital Maastricht and Maastricht University, the Netherlands. Written informed consent was obtained from all participants.

Data collection. When designing the EnCoRe study, an ICF-based conceptual model was developed for studying lifestyle and HRQoL in colorectal cancer survivors (38). This conceptual model was adapted for the current research question to identify relevant variables to be measured and included in data analyses (Fig. 2).

Physical activity. The Short QUestionnaire to ASsess Health-enhancing physical activity (SQUASH) was used to measure habitual PA by assessing the frequency $\left(\mathrm{d} \cdot \mathrm{wk}^{-1}\right)$, duration (time per day), and intensity (light, moderate, vigorous) of commuting (walking and cycling), household, work, and leisure activities (cycling, walking, gardening, odd jobs, and up to four sports) in the previous week (43). For commuting and leisure activities, intensity levels were enquired as slow, moderate, or fast, for classification as light, moderate, or vigorous, respectively. In order to keep the questionnaire short and easy to fill in, household and work activities were structured into two categories of intensity, which were defined and explained by examples, as either light-intensity (sitting or standing work with occasional walking, e.g., cooking, or a desk job) or vigorous-intensity (e.g., scrubbing floor, or regularly lifting heavy objects at work). According to standard procedures for the SQUASH questionnaire (43), Ainsworth's compendium of physical activities was used to assign METvalues to different activities (2). Based on the MET-value assigned and the intensity reported, activities were categorized as either LPA $(<3$ MET with self-reported light or moderate intensity, e.g., light household or light work activities [both, MET $=2.5$ ], jet skiing [MET $=2.5$ ] with a low or moderate intensity), or MVPA ( $\geq 3$ MET, or $<3$ MET with self-reported vigorous intensity, e.g., vigorous household or vigorous work activities $[\mathrm{MET}=4.5$ and $\mathrm{MET}=4.0$, respectively], walking [MET $=3.5$ ], or jet skiing $[\mathrm{MET}=2.5$ ] with a vigorous intensity). Within our sample, participants did not report performing any activities $<3$ MET with a vigorous intensity, and therefore these activities were always classified as LPA and never as MVPA. Total time spent in LPA and MVPA in $\mathrm{h} \cdot \mathrm{wk}^{-1}$ was calculated by multiplying the frequency and duration of all activities and summing these up separately. Validation studies in Dutch general and elderly populations have shown that the SQUASH is a fairly reliable questionnaire to assess PA and that its validity in comparison to accelerometer data is comparable to other PA questionnaires (in a Dutch elderly population: Spearman $\rho=0.56$ for $\min \cdot \mathrm{wk}^{-1}$ of total activity, 0.20 for light intensity activities, 0.40 for moderate intensity activities, and 0.35 for vigorous activities) $(42,43)$. 


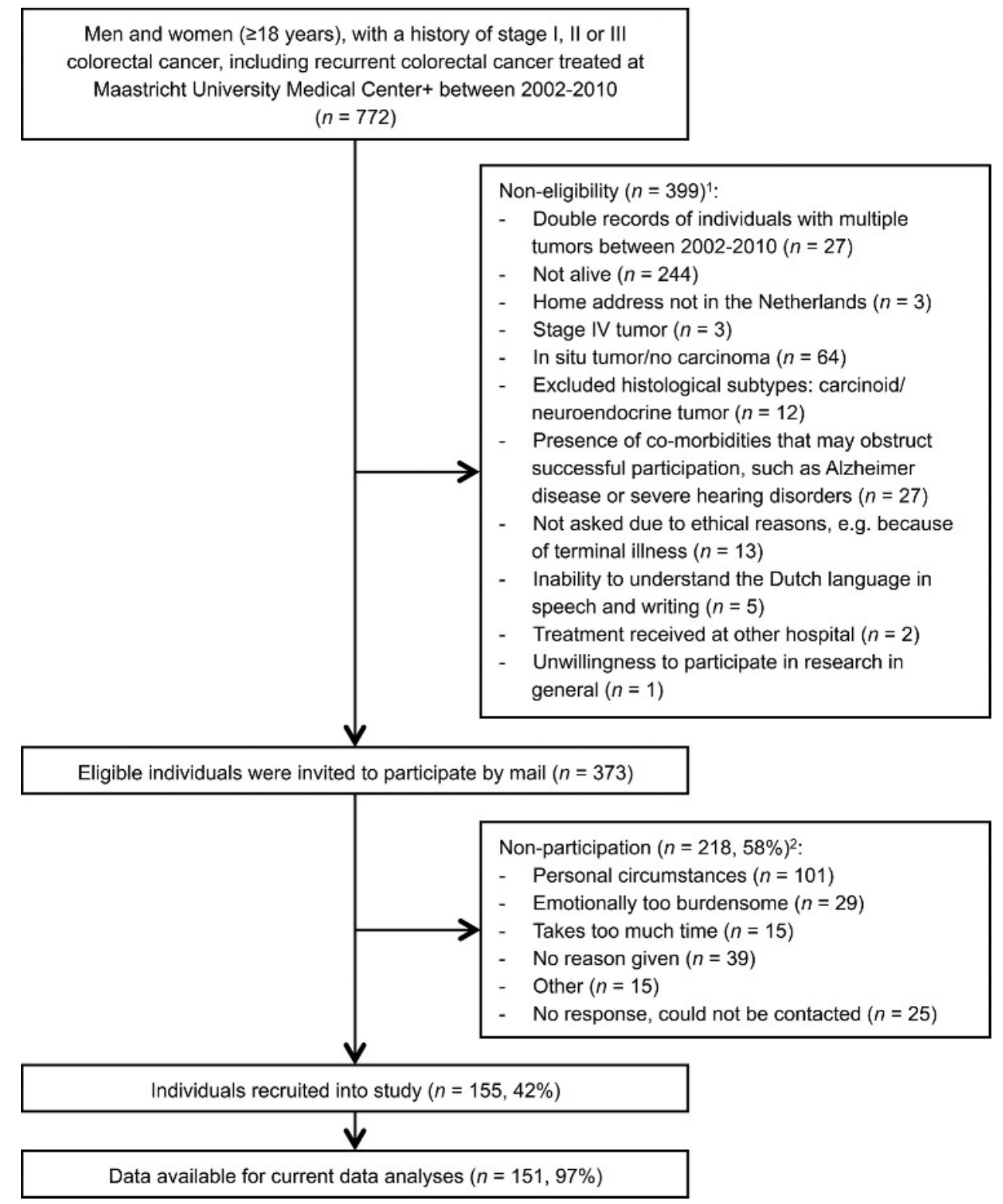

FIGURE 1-Flow diagram of inclusion of individuals into the cross-sectional part of the EnCoRe study and analyses presented in this paper. ${ }^{1}$ Reasons for noneligibility are given in order of exclusion; totals do not add up because some exclusion criteria applied concurrently. ${ }^{2}$ Totals do not add up because some individuals reported multiple reasons for nonparticipation.

HRQoL outcomes. Cancer-specific HRQoL was measured with the European Organization for the Research and Treatment of Cancer Quality of Life Questionnaire-Core 30 (EORTC QLQ-C30, version 3.0), which is a reliable and valid measure for HRQoL in patients with cancer $(1,3)$. For the subscales global health/quality of life and physical, role and social functioning, 100-point scores were calculated with higher scores indicating higher levels of quality of life or functioning (13). Furthermore, disability was assessed by the 12-item version of the ICF-based World Health Organization Disability Assessment Schedule II (WHODAS II) $(37,45)$. The WHODAS II has a good reliability and validity in different populations, including elderly individuals and breast cancer survivors $(25,33,45)$. A weighted disability score (100-point scale) was calculated, with a higher score indicating a higher level of disability (45). In addition, selfreported fatigue was assessed through the Checklist Individual Strength (CIS), which was originally developed and validated in patients with chronic fatigue syndrome $(39,40)$ but has also been applied in cancer survivors (30). We used the Hospital Anxiety and Depression Scale (HADS) to determine levels of anxiety and depression (46), which has adequate psychometric properties in patients with cancer (41). Individual items from the CIS and HADS were summed to calculate a total score for fatigue (range, 20-140) and distress $(0-42)$, respectively, with higher scores indicating higher levels of fatigue and distress.

Other factors. From our ICF-based conceptual model (Fig. 2), other relevant factors for studying associations between PA and HRQoL in colorectal cancer survivors were 


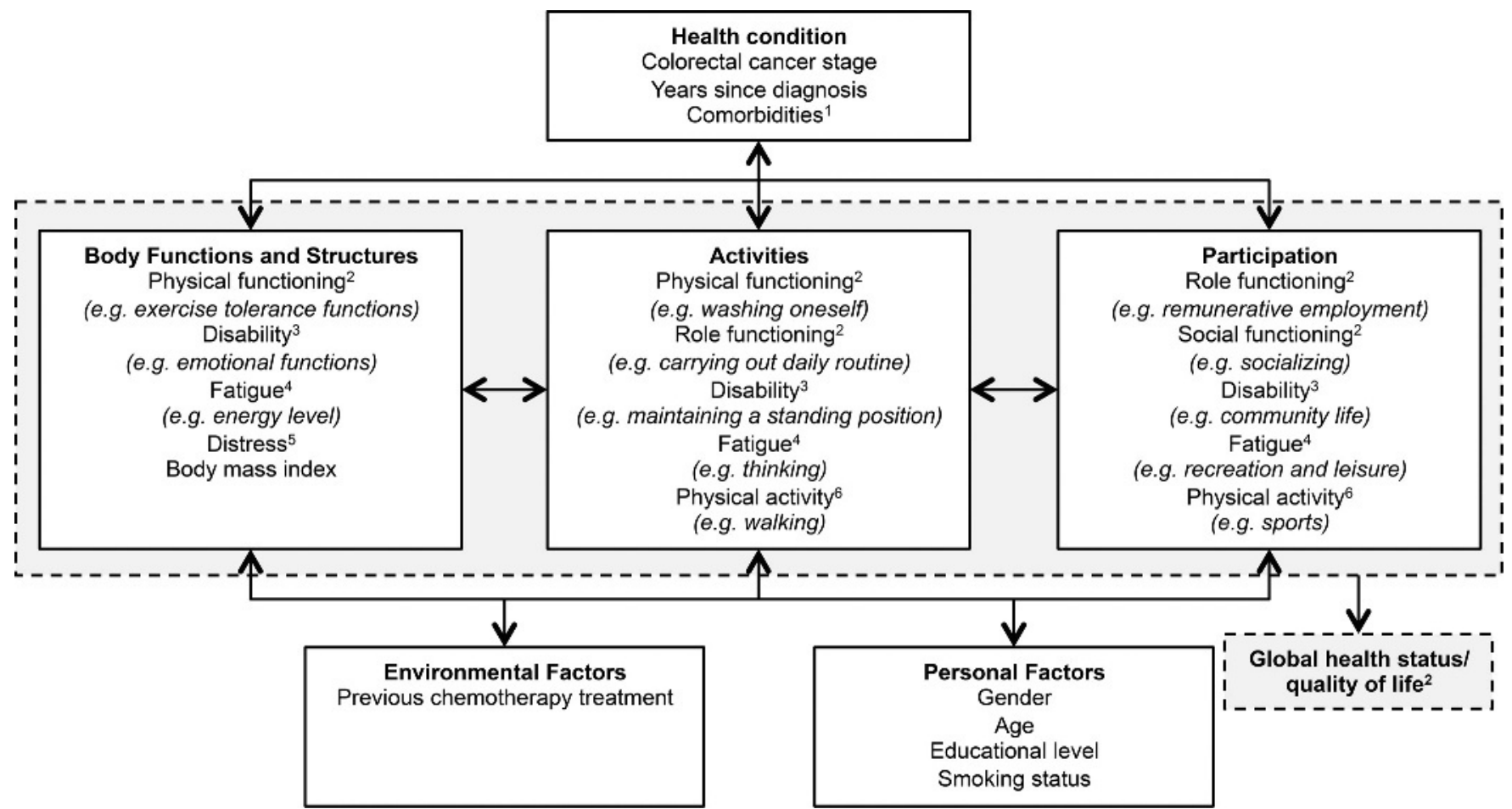

FIGURE 2-ICF-based conceptual model showing relevant factors for studying PA and HRQoL outcomes in colorectal cancer survivors, which were measured within the cross-sectional part of the EnCoRe study and included in the current analyses. Certain HRQoL outcomes are shown within multiple ICF domains for functioning (e.g., physical functioning is shown in both "Body functions and Structures" and "Activities"), because meaningful concepts contained in these measures were linked to specific ICF categories within these different domains of functioning (e.g., "exercise tolerance functions' and 'washing oneself”) (38). Measurement instruments: ${ }^{1}$ Self-Administered Comorbidity Questionnaire; ${ }^{2}$ European Organization for the Research and Treatment of Cancer Quality of Life Questionnaire-Core 30 (EORTC QLQ-C30); ${ }^{3} 12$-item World Health Organization Disability Assessment Schedule II (WHODAS II); ${ }^{4}$ Checklist Individual Strength (CIS); ${ }^{5}$ Hospital Anxiety and Depression Scale (HADS); ${ }^{6}$ Short QUestionnaire to ASsess Health-enhancing physical activity (SQUASH).

identified and measured. Sociodemographic characteristics (sex, age, education level, smoking status) were self-reported, whereas body height and weight were measured by trained personnel for calculation of body mass index (BMI). Presence of comorbidities was assessed using the Self-Administered Comorbidity Questionnaire (27). Data on clinical characteristics (cancer stage, age at diagnosis, chemotherapy treatment) were collected through the NCR.

Statistical analyses. Descriptive statistics were calculated to compare sociodemographic and clinical characteristics of participants by quartiles of time spent in LPA and MVPA. Multivariable linear regression models were used to calculate adjusted mean differences (MDs) (with 95\% confidence intervals [CIs]) in HRQoL scores between LPA or MVPA quartiles, with the lowest quartile as reference category. Testing for a linear trend across quartiles was performed by including an ordinal variable with the median value of time spent in LPA or MVPA in each quartile in the regression models. A hierarchical approach was applied by fitting unadjusted, age- and sex-adjusted, and fully adjusted models. Covariates included in fully adjusted models were selected a priori from our ICF-based conceptual model (Fig. 2), comprising age, sex, number of comorbidities, years since diagnosis, tumor stage, current smoking status, BMI, chemotherapy treatment, and education level. In addition, to assess independent associations of LPA and MVPA with HRQoL outcomes, time spent in MVPA $\left(\mathrm{h} \cdot \mathrm{wk}^{-1}\right)$ was included as a covariate for the analyses of LPA and vice versa. These fully adjusted models were considered our main results.

To further compare the separate associations of time spent in LPA and MVPA with the HRQoL outcomes, multivariable analyses were repeated, including a categorical variable with four combinations of LPA and MVPA: low LPA and low MVPA (reference category); high LPA and low MVPA; low LPA and high MVPA; and high LPA and high MVPA. This variable was created by dichotomizing the variables for time spent in LPA and MVPA using the median value as cutoff, and these dichotomized variables were combined into one variable with four categories. All HRQoL outcome scores, except for fatigue and distress, were not normally distributed, and therefore, sensitivity analyses were performed by fitting logistic regression models with dichotomized outcomes, using a sex-specific median value as cutoff (28). In addition, potential effect modification by sex, age ( $<70 \mathrm{vs} \geq 70 \mathrm{yr}$ ), and number of comorbidities ( $\geq 2 \mathrm{vs}<2$ ) was explored by performing subgroup analyses and including cross-product terms into linear regression models to test for statistical interaction. To avoid overinterpretation of spurious findings, subgroup results were only reported if a statistically significant difference in multiple HRQoL scores 
was found between the lowest and both the third and fourth quartile of LPA or MVPA in one subgroup, but not in the other subgroup. Analyses were performed using IBM SPSS Statistics version 20 (IBM Corporation, 2011), and $P<0.05$ were considered statistically significant.

\section{RESULTS}

Participant characteristics. A total of 373 eligible colorectal cancer survivors were invited to participate, of whom 155 were recruited (response rate, 42\%; Fig. 1). Of these, 4 survivors (3\%) did not provide PA data, resulting in a final number of 151 participants included in current analyses. Participants were on average 3.9 yr younger, had more often been diagnosed with rectal cancer ( $42 \%$ vs $36 \%$ ), and had more frequently received treatment with chemotherapy $(52 \%$ vs $43 \%)$ and radiotherapy (39\% vs $30 \%)$, than nonparticipants (not included or without PA data; see Table S1, Supplemental Digital Content 1, Socio-demographic and clinical characteristics of eligible colorectal cancer survivors included and not included in the current analyses, http://links.lww.com/MSS/A547). No relevant differences were observed in sex, years since diagnosis, and tumor stage.

A total of 94 male (62\%) and 57 female (38\%) colorectal cancer survivors were included, who were on average $69.8 \mathrm{yr}$ of age (standard deviation [SD], 8.7) and $5.7 \mathrm{yr}$ since colorectal cancer diagnosis (1.8). Of these, 80 survivors $(53 \%)$ had a previous diagnosis of colon cancer, 64 (42\%) rectum cancer, and $7(5 \%)$ a rectosigmoid tumor. In addition, 68 (45\%) survivors were overweight, 43 (29\%) were obese, and 38 (25\%) had normal weight; 1 participant was underweight. A total of 76 (51\%) survivors reported two or more comorbidities. The three most commonly reported comorbidities comprised hypertension (43\%), osteoarthritis $(33 \%)$, and back pain (28\%).

Self-reported mean time spent in LPA and MVPA was $15.0(\mathrm{SD}, 17.4)$ and $13.0(15.0) \mathrm{h} \cdot \mathrm{wk}^{-1}$, respectively. Based on total time spent in MVPA, 107 survivors $(71 \%)$ adhered to current PA guidelines (at least $150 \mathrm{~min}^{\mathrm{w}} \mathrm{wk}^{-1}$ of MVPA). Overall, highest levels were observed for light household activities (median, $7.0 \mathrm{~h} \cdot \mathrm{wk}^{-1}$; interquartile range [IQR], $1.0-16.2)$ and walking $(3.0 ; 0.0-5.5)$, whereas low levels were observed for commuting, vigorous household activities, work activities, cycling, gardening, odd jobs, and sports (all median, $0.0 \mathrm{~h} \cdot \mathrm{wk}^{-1}$ ). Participants were classified according to quartiles of time spent in LPA $(\mathrm{Q} 1, \leq 2.0 ; \mathrm{Q} 2$, 2.3-9.0; Q3, 10.0-22.0; and Q4, $\geq 23.0 \mathrm{~h} \cdot \mathrm{wk}^{-1}$ ) and MVPA (Q1, $\leq 4.3 ; \mathrm{Q} 2,4.5-8.6$; Q3, 8.7-15.0; and Q4, $\left.\geq 15.5 \mathrm{~h} \cdot \mathrm{wk}^{-1}\right)$. The correlation between LPA and MVPA, both as continuous variables and categorized into quartiles, was very weak and nonsignificant (Spearman $\rho=0.04 ; P=0.59$; and Kendall $\tau=0.06 ; P=0.40$ ).

Individuals in the highest quartiles of LPA and MVPA were on average younger (MD Q4 vs Q1, -7.6; and -2.6 yr, respectively) and less frequently reported multiple comorbidities than in lower quartiles (Q4 vs Q1, 47\% vs 62\%; and
$22 \%$ vs $65 \%$, respectively; Table 1). Compared to the lowest quartile, there were more women in the highest quartile of LPA $(62 \%$ vs $13 \%)$, whereas there were more men in the highest quartile of MVPA ( $78 \%$ vs $51 \%$ ). Within the highest quartile of LPA, most time was spent on household activities (median, $28.0 \mathrm{~h} \cdot \mathrm{wk}^{-1}$; IQR, 8.6-35.0), whereas in the highest quartile of MVPA, most time was spent on leisure activities $(21.0 ; 16.8-31.0)$. Generally, participants in the highest quartiles of LPA and MVPA reported higher HRQoL and lower disability, distress, and fatigue scores than those in the lowest quartiles (Table 2). The HRQoL outcomes were moderately to strongly correlated, with positive correlations between the global health status/quality of life, and physical, role, and social functioning scores (Spearman $\rho$ ranging from 0.45 to 0.67 ), and between the disability, fatigue, and distress scores (Spearman $\rho$ ranging from 0.59 to 0.74 ), and negative correlations between the global health status/quality of life, and physical, role and social functioning on the one hand, and disability, fatigue, and distress scores on the other hand (Spearman $\rho$ ranging from -0.41 to -0.73 ).

Multivariable analyses. Results from fully adjusted linear regression models analyzing relationships between quartiles of LPA and MVPA, and HRQoL outcome scores were in general slightly attenuated in comparison to age- and sexadjusted models (see Table S2, Supplemental Digital Content 2, Age- and sex-adjusted, and fully adjusted mean differences and 95\% CIs in health-related quality of life scores across quartiles of time spent in LPA and MVPA $\left(\mathrm{h} \cdot \mathrm{wk}^{-1}\right)$ in colorectal cancer survivors, http://links.lww.com/MSS/A548). In fully adjusted models (Fig. 3), increasing quartiles of LPA and MVPA were independently associated with higher physical functioning (MD Q4 vs Q1, 10.2; 95\% CI, 0.2-20.3; and 14.5; 5.1-23.9, respectively; both $P$-trend $<0.05$ ). In addition, increasing quartiles of LPA were significantly associated with higher role functioning and lower disability (MD Q4 vs Q1, 19.5; 95\% CI, 6.9-32.1; and $-9.9 ;-17.8$ to -1.9 , respectively; both $P$-trend $<0.05$ ), independent from MVPA. Furthermore, the third quartile of LPA was significantly associated with lower fatigue than the lowest quartile (MD Q3 vs Q1, -16.2 ; $95 \%$ CI, -29.5 to -3.0 ), but no significant difference was found between the highest and lowest quartile. Similarly, relative to the lowest quartile, the third quartile of MVPA was significantly associated with higher role (MD Q3 vs Q1, 13.3; 95\% CI, 1.6-25.1) and social functioning $(11.0 ; 1.9-20.1)$, and lower disability $(-8.5$; -15.7 to -1.3$)$, fatigue $(-16.0 ;-28.5$ to -3.6$)$, and distress $(-2.9 ;-5.7$ to -0.1$)$, but no significant difference was found between the highest and lowest quartile. No associations were observed between LPA and MVPA and the global health status/quality of life subscale. In all multivariable models, the presence of multiple comorbidities as covariate had the strongest attenuating effect on associations between PA and HRQoL and was significantly associated with lower HRQoL and higher disability, fatigue, and distress scores $(P<0.05)$. 
TABLE 1. Sociodemographic, clinical, and PA characteristics of colorectal cancer survivors by quartiles of time spent in LPA and MVPA.

\begin{tabular}{|c|c|c|c|c|c|c|c|c|c|}
\hline & \multicolumn{4}{|c|}{ Quartiles of LPA (h.wk $\left.{ }^{-1}\right)$} & \multicolumn{4}{|c|}{ Quartiles of MVPA (h.wk ${ }^{-1}$ ) } & \multirow{3}{*}{$\frac{\text { Total Sample }}{(n=151)}$} \\
\hline & Q1 & Q2 & Q3 & Q4 & Q1 & Q2 & Q3 & Q4 & \\
\hline & $(n=39)$ & $(n=36)$ & $(n=39)$ & $(n=37)$ & $(n=37)$ & $(n=38)$ & $(n=39)$ & $(n=37)$ & \\
\hline \multicolumn{10}{|c|}{ Sociodemographic and clinical variables } \\
\hline Age $(y)$, mean (SD) & $73.2(7.9)$ & $72.3(8.4)$ & $68.1(7.4)$ & $65.6(9.1)$ & $70.8(10.0)$ & $72.0(9.2)$ & $68.1(8.1)$ & $68.2(6.9)$ & $69.8(8.7)$ \\
\hline Years since diagnosis, mean (SD) & $5.6(1.7)$ & $5.9(1.9)$ & $6.1(2.0)$ & $5.3(1.7)$ & $6.1(1.7)$ & $5.7(1.9)$ & $5.0(1.6)$ & $6.0(2.0)$ & $5.7(1.8)$ \\
\hline \multicolumn{10}{|l|}{ Sex, $n(\%)$} \\
\hline Men & $34(87.2)$ & $24(66.7)$ & $22(56.4)$ & $14(37.8)$ & $19(51.4)$ & $24(63.2)$ & $22(56.4)$ & $29(78.4)$ & $94(62.3)$ \\
\hline Women & $5(12.8)$ & $12(33.3)$ & $17(43.6)$ & $23(62.2)$ & $18(48.6)$ & $14(36.8)$ & $17(43.6)$ & $8(21.6)$ & $57(37.7)$ \\
\hline \multicolumn{10}{|l|}{ Tumor stage, $n(\%)$} \\
\hline 1 & $9(25.0)$ & $8(22.9)$ & $12(34.3)$ & $13(35.1)$ & $13(36.1)$ & $9(24.3)$ & $13(34.2)$ & $7(21.9)$ & $42(29.4)$ \\
\hline II & $13(36.1)$ & $15(42.9)$ & $13(37.1)$ & $11(29.7)$ & $11(30.6)$ & $16(43.2)$ & $12(31.6)$ & $13(40.6)$ & $52(36.4)$ \\
\hline III & $14(38.9)$ & $12(34.3)$ & $10(28.6)$ & $13(35.1)$ & $12(33.3)$ & $12(32.4)$ & $13(34.2)$ & $12(37.5)$ & $49(34.3)$ \\
\hline \multicolumn{10}{|l|}{ Treatment with chemotherapy, $n$ (\%) } \\
\hline Yes & $19(48.7)$ & $20(55.6)$ & $20(51.3)$ & $20(54.1)$ & $16(43.2)$ & $16(42.1)$ & $24(61.5)$ & $23(62.2)$ & $79(52.3)$ \\
\hline No & $20(51.3)$ & $16(44.4)$ & $19(48.7)$ & $17(45.9)$ & $21(56.8)$ & $22(57.9)$ & $15(38.5)$ & $14(37.8)$ & $72(47.7)$ \\
\hline \multicolumn{10}{|l|}{ No. comorbid conditions, $n(\%)$} \\
\hline None & $5(12.8)$ & $11(30.6)$ & $10(25.6)$ & $11(30.6)$ & $5(13.5)$ & $5(13.2)$ & $11(28.2)$ & $16(44.4)$ & $37(24.7)$ \\
\hline 1 & $10(25.6)$ & $10(27.8)$ & $9(23.1)$ & $8(22.2)$ & $8(21.6)$ & $8(21.1)$ & $9(23.1)$ & $12(33.3)$ & $37(24.7)$ \\
\hline$\geq 2$ & $24(61.5)$ & $15(41.7)$ & $20(51.3)$ & 17 (47.2) & $24(64.9)$ & $25(65.8)$ & $19(48.7)$ & $8(22.2)$ & $76(50.7)$ \\
\hline $\mathrm{BMI}\left(\mathrm{kg} \cdot \mathrm{m}^{-2}\right)$, mean (SD) & $27.5(3.7)$ & $26.7(4.1)$ & $29.3(5.4)$ & $27.2(3.4)$ & $28.8(5.1)$ & $27.7(3.9)$ & $27.0(4.0)$ & $27.4(4.2)$ & $27.7(4.3)$ \\
\hline \multicolumn{10}{|l|}{ Education level, $n(\%)$} \\
\hline Low & 7 (17.9) & $9(25.0)$ & $9(23.1)$ & $12(32.4)$ & $12(32.4)$ & 7 (18.4) & $8(20.5)$ & $10(27.0)$ & $37(24.5)$ \\
\hline Medium & $15(38.5)$ & $12(33.3)$ & $13(33.3)$ & $12(32.4)$ & $13(35.1)$ & $13(34.2)$ & $13(33.3)$ & $13(35.1)$ & $52(34.4)$ \\
\hline High & $17(43.6)$ & $15(41.7)$ & 17 (43.6) & $13(35.1)$ & $12(32.4)$ & $18(47.4)$ & $18(46.2)$ & $14(37.8)$ & $62(41.1)$ \\
\hline \multicolumn{10}{|l|}{ Smoking status, $n(\%)$} \\
\hline Current & $4(10.3)$ & $3(8.3)$ & $3(7.7)$ & $6(16.2)$ & 7 (18.9) & $3(7.9)$ & $2(5.1)$ & $4(10.8)$ & $16(10.6)$ \\
\hline Former & $31(79.5)$ & $25(69.4)$ & $26(66.7)$ & $21(56.8)$ & $20(54.1)$ & $29(76.3)$ & 27 (69.2) & $27(73.0)$ & $103(68.2)$ \\
\hline Never & $4(10.3)$ & $8(22.2)$ & $10(25.6)$ & $10(27.0)$ & $10(27.0)$ & $6(15.8)$ & $10(25.6)$ & $6(16.2)$ & $32(21.1)$ \\
\hline \multicolumn{10}{|l|}{ PA variables $\left(h \cdot w^{-1}\right)$} \\
\hline LPA, median & 0.0 & 6.0 & 15.8 & 35.0 & 8.8 & 6.1 & 14.0 & 10.5 & 10.0 \\
\hline IQR & $0.0-1.2$ & $4.0-7.0$ & $11.5-21.0$ & $28.0-43.0$ & $1.1-24.8$ & $0.0-22.8$ & $3.5-28.0$ & $4.3-20.0$ & $2.0-22.0$ \\
\hline Range & $0.0-2.0$ & $2.3-9.0$ & $10.0-22.0$ & $23.0-134.0$ & $0.0-134.0$ & $0.0-67.0$ & $0.0-40.0$ & $0.0-42.0$ & $0.0-134.0$ \\
\hline MVPA, median & 7.3 & 7.1 & 12.5 & 8.5 & 2.8 & 6.5 & 11.0 & 24.0 & 8.7 \\
\hline IQR & $3.5-12.0$ & $4.3-19.4$ & $7.0-17.8$ & $4.1-12.8$ & $0.8-3.5$ & $5.3-7.5$ & $10.0-13.5$ & $17.9-41.6$ & $4.5-15.0$ \\
\hline Range & $0.0-82.0$ & $0.0-57.3$ & $0.0-92.0$ & $0.0-75.0$ & $0.0-4.3$ & $4.5-8.6$ & $8.7-15.0$ & $15.5-92.0$ & $0.0-92.0$ \\
\hline Commuting, median & 0.0 & 0.0 & 0.0 & 0.0 & 0.0 & 0.0 & 0.0 & 0.0 & 0.0 \\
\hline IQR & $0.0-0.0$ & $0.0-0.0$ & $0.0-0.0$ & $0.0-0.4$ & $0.0-0.0$ & $0.0-0.0$ & $0.0-0.0$ & $0.0-0.0$ & $0.0-0.0$ \\
\hline Work, median & 0.0 & 0.0 & 0.0 & 0.0 & 0.0 & 0.0 & 0.0 & 0.0 & 0.0 \\
\hline IQR & $0.0-0.0$ & $0.0-0.0$ & $0.0-8.0$ & $0.0-29.5$ & $0.0-2.0$ & $0.0-0.0$ & $0.0-8.0$ & $0.0-0.0$ & $0.0-0.0$ \\
\hline Household activities, median & 0.0 & 6.0 & 14.0 & 28.0 & 5.9 & 4.0 & 8.8 & 11.2 & 7.0 \\
\hline IQR & $0.0-1.8$ & $3.5-7.5$ & $9.0-18.0$ & $8.6-35.0$ & $1.0-17.9$ & $0.0-11.6$ & $2.0-17.5$ & $2.8-19.0$ & $1.7-17.6$ \\
\hline Leisure activities, median & 7.0 & 8.0 & 10.0 & 8.5 & 2.7 & 6.8 & 10.0 & 21.0 & 8.5 \\
\hline IQR & $4.3-11.5$ & $4.3-18.4$ & $3.5-17.0$ & $3.3-11.0$ & $1.0-3.5$ & $5.0-8.0$ & $9.0-12.0$ & $16.8-31.0$ & $3.9-13.8$ \\
\hline
\end{tabular}

Q, quartile.

In multivariable analyses including the variable in which LPA and MVPA levels were combined (Table 3), both the categories "high LPA and low MVPA" and "low LPA and high MVPA," in comparison with the reference category "low LPA and low MVPA," were associated with significantly higher physical, role, and social functioning, and significantly lower disability, fatigue, and distress scores. The MDs for these categories were mostly similar to or larger than those obtained for the category "high LPA and high MVPA," in comparison with "low LPA and low MVPA." Results obtained from logistic regression models with dichotomized HRQoL scores were similar to those from linear regression models, except for the relation between LPA and physical functioning, which was not significant (results not shown).

Subgroup analyses. We observed different associations between LPA and multiple HRQoL outcomes in subgroups of

TABLE 2. HRQoL scores of colorectal cancer survivors by quartiles of time spent in LPA and MVPA

\begin{tabular}{|c|c|c|c|c|c|c|c|c|c|}
\hline \multirow[b]{4}{*}{ HRQoL Outcome (Score Range) } & \multicolumn{4}{|c|}{ Quartiles of LPA (h.wk ${ }^{-1}$ ) } & \multicolumn{4}{|c|}{ Quartiles of MVPA (h.wk ${ }^{-1}$ ) } & \multirow{3}{*}{$\begin{array}{c}\text { Total Sample } \\
(n=151)\end{array}$} \\
\hline & Q1 & Q2 & Q3 & Q4 & Q1 & Q2 & Q3 & Q4 & \\
\hline & $(n=39)$ & $(n=36)$ & $(n=39)$ & $(n=37)$ & $(n=37)$ & $(n=38)$ & $(n=39)$ & $(n=37)$ & \\
\hline & $\overline{\text { Mean (SD) }}$ & $\overline{\text { Mean (SD) }}$ & $\overline{\text { Mean (SD) }}$ & $\overline{\text { Mean (SD) }}$ & $\overline{\text { Mean (SD) }}$ & $\overline{\text { Mean (SD) }}$ & $\overline{\text { Mean (SD) }}$ & $\overline{\text { Mean (SD) }}$ & Mean (SD) \\
\hline Global health status/quality of life $(0-100)$ & $74.6(22.8)$ & $81.0(14.0)$ & $78.8(15.5)$ & $75.9(18.5)$ & $72.5(22.8)$ & $74.8(18.0)$ & $80.8(15.5)$ & $82.0(13.8)$ & $77.6(18.1)$ \\
\hline Physical functioning $(0-100)$ & $75.3(27.0)$ & $78.5(22.8)$ & $84.4(15.3)$ & $83.8(13.9)$ & $65.6(24.3)$ & $78.0(20.2)$ & $89.4(12.4)$ & $88.6(14.7)$ & $80.5(20.6)$ \\
\hline Role functioning $(0-100)$ & $73.1(31.0)$ & $84.3(26.7)$ & $86.3(19.8)$ & $89.2(19.3)$ & $72.5(32.9)$ & $79.8(24.6)$ & $89.3(18.9)$ & $90.5(18.7)$ & $83.1(25.2)$ \\
\hline Social functioning $(0-100)$ & $81.6(26.4)$ & $92.6(15.7)$ & $92.3(12.0)$ & $89.6(16.8)$ & $82.4(25.4)$ & $86.4(21.9)$ & $94.4(11.0)$ & $92.3(11.5)$ & $89.0(18.9)$ \\
\hline Distress (0-42) & $9.4(6.6)$ & $8.0(5.9)$ & $8.1(5.5)$ & $7.9(6.1)$ & $10.0(6.7)$ & $8.6(5.9)$ & $6.6(5.3)$ & $8.3(5.9)$ & $8.4(6.0)$ \\
\hline
\end{tabular}

$Q$, quartile. 
Global health status/quality of life

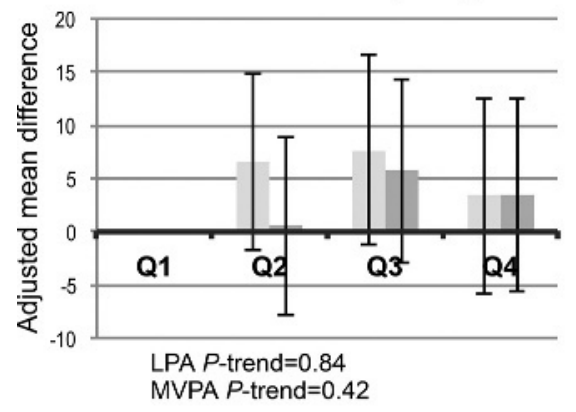

Social functioning

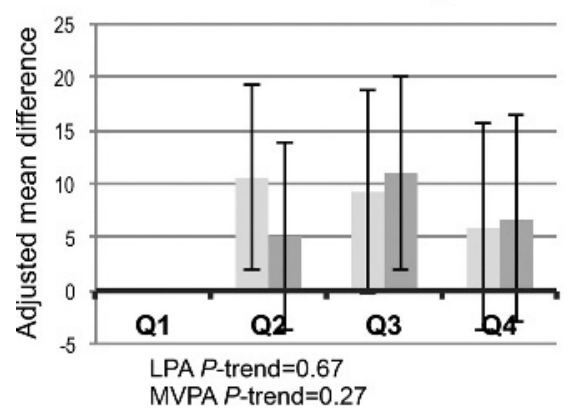

Distress

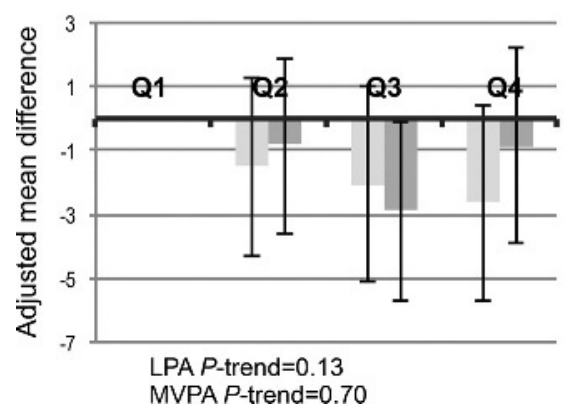

Physical functioning

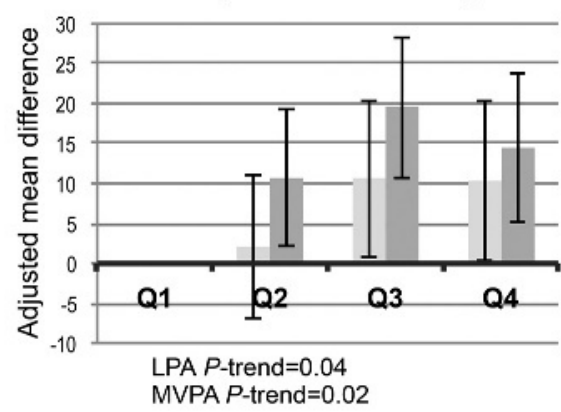

Disability

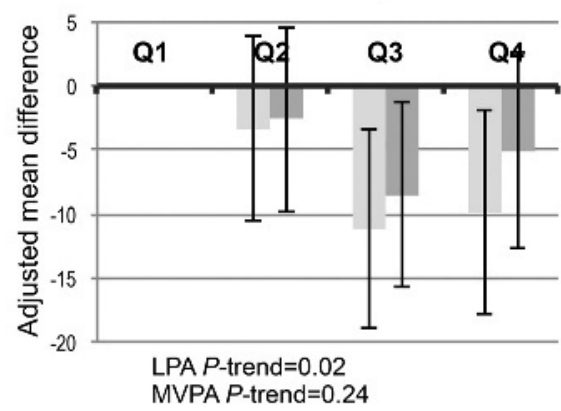

LPA $P$-trend $=0.02$

week $^{-1}$ )
Role functioning

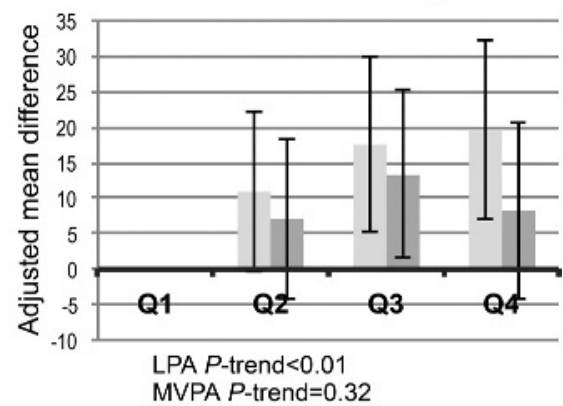

Fatigue

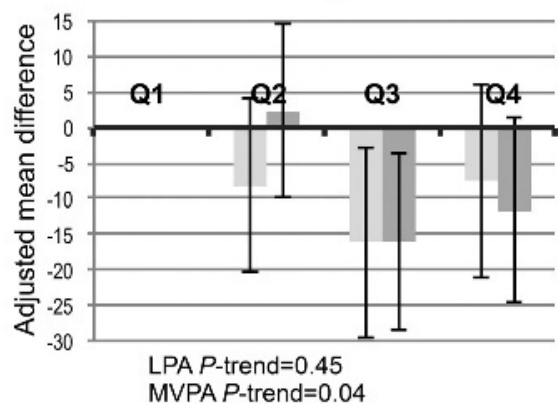

FIGURE 3-Adjusted MDs in HRQoL outcome scores between quartiles of time spent in LPA $(Q 1, \leq 2.0 ;$ Q2, 2.3-9.0; Q3, 10.0-22.0; and Q4,

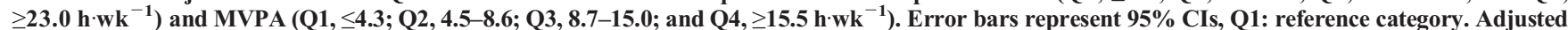
for age (yr), sex, number of comorbidities (0/1/ $\geq 2)$, years since diagnosis (yr), tumor stage (I/II/III), smoking status (current/noncurrent), BMI (kg. $\mathrm{m}^{-2}$ ), received chemotherapy (yes/no), education level (low/medium/high), and time spent in MVPA or LPA (hwk ${ }^{-1}$ ) for the analyses of LPA or MVPA, respectively.

sex and number of comorbidities (results not shown). LPA was significantly associated with higher physical functioning and lower disability in women (MD Q4 vs Q1, 22.2; 95\% CI, $0.2-44.1$; and $-32.0 ;-55.7$ to -8.3 , respectively), but not in men $(2.2 ;-11.0$ to 15.3 ; and $-2.5 ;-12.2$ to 7.3 , respectively; both $P$-interaction $<0.05)$. Significant associations were also observed between LPA and higher role and social functioning in women (MD Q4 vs Q1, 50.1; 95\% CI, 19.680.7; and 22.8; 7.6-38.1, respectively), but not in men (11.7; -3.9 to 27.3 ; and $-2.3 ;-17.3$ to 12.6 , respectively), although statistical interaction between sex and LPA was not significant ( $P$-interaction $=0.08$ and 0.35 , respectively). Similarly, we observed significant associations between LPA and higher physical and role functioning, and lower disability in survivors with $\geq 2$ comorbidities (MD Q4 vs Q1, 21.3; 95\% CI, 7.4-35.1; 22.0; 1.9-42.0; and $-17.7 ;-30.8$ to -4.6 , respectively), but not in individuals with $<2$ comorbidities
$(-2.2 ;-17.2$ to $12.8 ; 13.7 ;-2.4$ to 29.8 ; and $-1.6 ;-11.0$ to 7.9 , respectively), although statistical interaction between LPA and comorbidity was not significant $(P$-interaction $=$ $0.05,0.45$, and 0.28 , respectively).

\section{DISCUSSION}

In this cross-sectional study, we investigated associations between self-reported time spent in LPA and MVPA, and multiple HRQoL outcomes in 2- to 10-yr postdiagnosis colorectal cancer survivors. We found that both LPA and MVPA were independently associated with higher physical functioning and that LPA was also associated with higher role functioning and lower disability. In addition, our findings suggested that LPA may be associated with lower fatigue, and MVPA with higher role and social functioning, and lower disability, fatigue and distress. Significant differences were observed 
between the first and third but not the fourth quartile of LPA and MVPA. This suggests potential nonlinear associations. Furthermore, we observed that both combinations of high LPA and low MVPA, and low LPA and high MVPA, were associated with significantly higher physical, role, and social functioning, and lower disability, fatigue, and distress, in comparison with low LPA and low MVPA. These cross-sectional results are in line with our prior hypotheses that LPA and MVPA are associated with better HRQoL outcomes in colorectal cancer survivors but need to be further examined in prospective studies with larger sample sizes.

The MDs observed in role functioning scores between LPA quartiles and in physical and social functioning scores between MVPA quartiles exceeded thresholds of minimally important differences (MIDs) for the EORTC QLQ-C30 (14, 19 , and 11 for the physical, role, and social functioning subscales, respectively) (12). However, differences found between LPA or MVPA quartiles and the global health status/ quality of life subscale did not (MID, 10) (12). It could be speculated that the lack of meaningful differences in global health status/quality of life score is due to LPA and/or MVPA being more strongly associated with some HRQoL domains (physical, role, and social functioning) than others (cognitive and emotional functioning), which is reflected in a weaker association with overall HRQoL (global health status/quality of life). For the WHODAS II, CIS, and HADS, no guidelines for MIDs are available. The differences we observed between LPA and MVPA quartiles in disability and fatigue exceeded 0.5 times the SD within our population, which is generally regarded as MID in this case (26).

Two studies have previously investigated the relation between LPA and physical functioning in colorectal cancer survivors $(4,17)$. In one cross-sectional study, no associations were observed between LPA and physical functioning of colorectal cancer survivors, after adjustment for MVPA (17). However, within an intervention study in breast, prostate, and colorectal cancer survivors, positive associations were observed at baseline between LPA and several measures of physical functioning, independent from MVPA (4). Within our study, linear regression analyses showed that more time spent in LPA was associated with better physical functioning. However, as this association did not exceed MID guidelines and was not observed in sensitivity analyses using logistic regression with dichotomized HRQoL scores, it should be interpreted with caution. We observed that LPA was also associated with other HRQoL outcomes, such as role functioning and disability. Similarly, an observational study in a general population of elderly individuals observed that, independent from MVPA, increased time spent in LPA was positively associated with physical health and psychosocial well-being, which further supports the potential beneficial effect of LPA (10). For MVPA, our results are consistent with those of previous observational studies, in which MVPA was favorably associated with multiple HRQoL outcomes in colorectal cancer survivors, such 
as higher physical functioning and lower levels of fatigue $(9,15,17,20,23,36)$.

Importantly, subgroup analyses showed that associations between LPA and HRQoL were mainly observed in women and survivors with multiple comorbidities. In a previous study that also investigated associations between LPA and physical functioning, no significant interaction between LPA and sex was found (4). The underlying explanation is unknown and needs to be further explored. It is possible that women and survivors with multiple comorbidities have difficulties in achieving higher levels of PA after treatment for colorectal cancer. Increasing time spent in LPA, rather than MVPA, might be a more realistic target for lifestyle interventions in these subgroups of colorectal cancer survivors. Our crosssectional subgroup analyses were of an exploratory nature, and therefore, our findings need to be investigated in future prospective studies with larger sample sizes.

The two previous studies assessing self-reported LPA in colorectal cancer survivors $(4,17)$ both applied the Community Health Activities Model Program for Seniors (CHAMPS) questionnaire, which includes leisure-time activities, walking, household activities, and exercise (32). We cannot directly compare self-reported levels of LPA of our study with these two previous studies, as these provided energyweighted LPA measures in MET-hours per week (4) and kilocalories per week (17). In addition, a comparison is further limited by differences in MET-value assigned to activities in the CHAMPS versus the SQUASH questionnaire. For example, leisure walking in the CHAMPS questionnaire is classified as LPA (MET value, 2.5) (32), whereas in the SQUASH questionnaire, it is classified as MVPA (METvalue, 3.5) (43). As leisure walking is often reported by colorectal cancer survivors (4), this might greatly influence LPA levels. Furthermore, differences in characteristics associated with LPA between study samples might also hamper comparison, as for example, the participants in the previous cross-sectional study (17) were on average much older than the participants in our study (mean age, $81.5 \mathrm{vs} 69.8 \mathrm{yr}$ in our sample). The levels of MVPA we found in our sample were much higher than those in previous studies in Canadian (23), Australian (20), and American colorectal cancer survivors (5), which observed percentages of survivors reporting adherence to PA guidelines ( $\geq 150 \mathrm{~min} \cdot \mathrm{wk}^{-1}$ of MVPA) of $26 \%, 39 \%$, and $35 \%$, respectively. The questionnaires used in these studies only included leisure-time activities and not vigorous household or work activities. However, as time spent in these activities was very low in our sample, we do not think this could entirely explain these differences. Similar as for LPA, differences in classification of activities as LPA and MVPA by different questionnaires might explain differences. Another reason might be a difference in selfreported PA levels in populations from different countries, as previous studies in Dutch colorectal cancer survivors, which used a different questionnaire from the SQUASH, observed similar mean levels of self-reported levels of MVPA as we found, of $11.1 \mathrm{~h} \cdot \mathrm{wk}^{-1}$ (9) and $13.6 \mathrm{~h} \cdot \mathrm{wk}^{-1}$ (15).
To our knowledge, this is the first study investigating independent associations between LPA, MVPA, and multiple HRQoL outcomes in colorectal cancer survivors based on an ICF-based biopsychosocial approach. This approach enabled us to systematically and comprehensively measure HRQoL, by incorporating not only physical but also qualitative aspects of health such as psychosocial outcomes (e.g. fatigue and depression) and societal participation (e.g. role and social functioning) (38). In addition, our ICF-based conceptual model facilitated identification of important contextual factors influencing associations between PA and HRQoL, such as potential confounding and effect modifying factors, which was used during data analyses and interpretation of results. Because of the cross-sectional design, we cannot draw any conclusions regarding causality and direction of observed associations. Prospective studies are needed to confirm whether increasing LPA or MVPA can improve HRQoL of colorectal cancer survivors. We observed some differences between participants and nonparticipants, which could limit the generalizability of our findings. We could speculate that survivors with a lower HRQoL and PA were probably less likely to participate, leading to an underestimation of real associations between PA and HRQoL. Furthermore, PA was measured by selfreport, which can be limited by recall bias and floor effects, especially for LPA (35), and by misclassification due to potential interindividual differences in reporting the perceived intensity level of the separate activities. Although the validity of measuring absolute PA levels by questionnaires is generally limited, the validity of ranking individuals according to relative PA levels is usually acceptable (14) as has also been found for the SQUASH questionnaire $(42,43)$. By analyzing time per week of LPA and MVPA in quartiles, we were able to group individuals with similar PA levels and compare these groups within our analyses. In addition, we did not assess sedentary behavior (e.g., television viewing), which has shown to be highly prevalent and associated with HRQoL in Australian colorectal cancer survivors (21). Objective PA measures, such as accelerometers, can provide a more precise and valid assessment of both PA and sedentary behavior $(19,35)$. Finally, our findings should be replicated in other studies, as we performed a large number of tests within our analyses that might have resulted in false-positive findings. However, the consistent pattern we observed of both LPA and MVPA being beneficially associated with multiple HRQoL outcomes in colorectal cancer survivors, which was in line with our prior hypotheses and findings from previous studies, suggests that these findings are not caused by mere chance and seem to represent true associations within this population.

In conclusion, in this cross-sectional study, we found that self-reported LPA, besides MVPA, was favorably related to multiple HRQoL outcomes in colorectal cancer survivors. Prospective studies, preferably with objective PA measurements, are warranted to further investigate whether LPA could be a suitable target for personalized 
lifestyle interventions to improve the HRQoL of colorectal cancer survivors.

This work is supported by a grant from the Stichting Alpe d'HuZes within the research program "Leven met kanker" of the Dutch Cancer Society (grant no. UM-2010-4867). E.H. van Roekel is financially supported by this grant, and by the GROW School for Oncology and Developmental Biology. M. J. L. Bours is partly supported by a grant from the Stichting Alpe d'HuZes within the research program "Leven met kanker" of the Dutch Cancer Society (grant no. UM-2012-5653), and partly by a grant from Kankeronderzoekfonds Limburg (part of Health Foundation Limburg; grant no. 00005739). J. J. L. Breedveld-Peters is also supported by the latter grant of Kankeronderzoekfonds Limburg.

\section{REFERENCES}

1. Aaronson NK, Ahmedzai S, Bergman B, et al. The European Organization for Research and Treatment of Cancer QLQ-C30: A quality-of-life instrument for use in international clinical trials in oncology. J Natl Cancer Inst. 1993;85(5):365-76.

2. Ainsworth BE, Haskell WL, Leon AS, et al. Compendium of physical activities: classification of energy costs of human physical activities. Med Sci Sports Exerc. 1993;25(1):71-80.

3. Bjordal K, de Graeff A, Fayers PM, et al. A 12 country field study of the EORTC QLQ-C30 (version 3.0) and the head and neck cancer specific module (EORTC QLQ-H\&N35) in head and neck patients. EORTC Quality of Life Group. Eur J Cancer. 2000;36(14):1796-807.

4. Blair CK, Morey MC, Desmond RA, et al. Light-intensity activity attenuates functional decline in older cancer survivors. Med Sci Sports Exerc. 2014;46(7):1375-83.

5. Blanchard CM, Courneya KS, Stein K. Cancer survivors' adherence to lifestyle behavior recommendations and associations with health-related quality of life: results from the American Cancer Society's SCS-II. J Clin Oncol. 2008;26(13):2198-204.

6. Bray F, Ren JS, Masuyer E, Ferlay J. Global estimates of cancer prevalence for 27 sites in the adult population in 2008. Int $J$ Cancer. 2013;132(5):1133-45.

7. Brown JC, Schmitz KH. The prescription or proscription of exercise in colorectal cancer care. Med Sci Sports Exerc. 2014;46(12): 2202-9.

8. Buffart LM, Galvao DA, Brug J, Chinapaw MJ, Newton RU. Evidence-based physical activity guidelines for cancer survivors: Current guidelines, knowledge gaps and future research directions. Cancer Treat Rev. 2014;40(2):327-40.

9. Buffart LM, Thong MS, Schep G, Chinapaw MJ, Brug J, van de Poll-Franse LV. Self-reported physical activity: Its correlates and relationship with health-related quality of life in a large cohort of colorectal cancer survivors. PLoS One. 2012;7(5):e36164.

10. Buman MP, Hekler EB, Haskell WL, et al. Objective lightintensity physical activity associations with rated health in older adults. Am J Epidemiol. 2010;172(10):1155-65.

11. Caravati-Jouvenceaux A, Launoy G, Klein D, et al. Health-related quality of life among long-term survivors of colorectal cancer: a population-based study. Oncologist. 2011;16(11):1626-36.

12. Cocks K, King MT, Velikova G, Martyn St-James M, Fayers PM, Brown JM. Evidence-based guidelines for determination of sample size and interpretation of the European Organisation for the Research and Treatment of Cancer Quality of Life Questionnaire Core 30. J Clin Oncol. 2011;29(1):89-96.

13. Fayers PM, Aaronson NK, Bjordal K, Groenvold M, Curran D, Bottomley A, on behalf of the EORTC Quality of Life Group. The EORTC QLQ-C30 Scoring Manual (3rd Edition). Brussels: European Organisation for Research and Treatment of Cancer; 2001.78 p.
The authors thank the EnCoRe study participants and research team (P. van der A-Wisselink, N. Wijckmans, D. O. Klein, Y. L. L. Vanlingen, C. M. J. Gielen, and A. G. E. Smeets), the registration teams of the Comprehensive Cancer Centre Netherlands and Comprehensive Cancer Centre South for the collection of data for the Netherlands Cancer Registry, and the scientific staff of the Comprehensive Cancer Centre Netherlands.

No potential conflicts of interest were disclosed.

The results of the present study do not constitute endorsement by the American College of Sports Medicine.

Author contributions are as follows: conception and design, All authors; acquisition of data, Eline H. van Roekel, Martijn J. L. Bours, José J. L. Breedveld-Peters, Silvia Sanduleanu, Geerard L. Beets, and Matty P. Weijenberg; analysis and interpretation of data, All authors; writing, review and/or revision of the manuscript, All authors.
14. Helmerhorst HJ, Brage S, Warren J, Besson H, Ekelund U. A systematic review of reliability and objective criterion-related validity of physical activity questionnaires. Int J Behav Nutr Phys Act. 2012;9:103.

15. Husson O, Mols F, Ezendam NP, Schep G, van de Poll-Franse LV. Health-related quality of life is associated with physical activity levels among colorectal cancer survivors: A longitudinal, 3-year study of the PROFILES registry. J Cancer Surviv. 2015;9(3):472-80.

16. Jansen L, Koch L, Brenner H, Arndt V. Quality of life among longterm ( $\geq 5$ years) colorectal cancer survivors - Systematic review. Eur $J$ Cancer. 2010;46(16):2879-88.

17. Johnson BL, Trentham-Dietz A, Koltyn KF, Colbert LH. Physical activity and function in older, long-term colorectal cancer survivors. Cancer Causes Control. 2009;20(5):775-84.

18. Kostanjsek N. Use of The International Classification of Functioning, Disability and Health (ICF) as a conceptual framework and common language for disability statistics and health information systems. BMC Public Health. 2011;11(4 Suppl):S3.

19. Lynch BM. Sedentary behavior and cancer: a systematic review of the literature and proposed biological mechanisms. Cancer Epidemiol Biomarkers Prev. 2010;19(11):2691-709.

20. Lynch BM, Cerin E, Owen N, Hawkes AL, Aitken JF. Prospective relationships of physical activity with quality of life among colorectal cancer survivors. J Clin Oncol. 2008;26(27):4480-7.

21. Lynch BM, Cerin E, Owen N, Hawkes AL, Aitken JF. Television viewing time of colorectal cancer survivors is associated prospectively with quality of life. Cancer Causes Control. 2011;22(8):1111-20.

22. Parry C, Kent EE, Mariotto AB, Alfano CM, Rowland JH. Cancer survivors: A booming population. Cancer Epidemiol Biomarkers Prev. 2011;20(10):1996-2005.

23. Peddle CJ, Au HJ, Courneya KS. Associations between exercise, quality of life, and fatigue in colorectal cancer survivors. Dis Colon Rectum. 2008;51(8):1242-8.

24. Phillips SM, Alfano CM, Perna FM, Glasgow RE. Accelerating translation of physical activity and cancer survivorship research into practice: recommendations for a more integrated and collaborative approach. Cancer Epidemiol Biomarkers Prev. 2014;23(5):687-99.

25. Posl M, Cieza A, Stucki G. Psychometric properties of the WHODASII in rehabilitation patients. Qual Life Res. 2007;16(9): 1521-31

26. Revicki D, Hays RD, Cella D, Sloan J. Recommended methods for determining responsiveness and minimally important differences for patient-reported outcomes. J Clin Epidemiol. 2008;61(2):102-9.

27. Sangha O, Stucki G, Liang MH, Fossel AH, Katz JN. The SelfAdministered Comorbidity Questionnaire: A new method to assess comorbidity for clinical and health services research. Arthritis Rheum. 2003;49(2):156-63.

28. Schlesinger S, Walter J, Hampe J, et al. Lifestyle factors and health-related quality of life in colorectal cancer survivors. Cancer Causes Control. 2014;25(1):99-110. 
29. Schmitz KH, Courneya KS, Matthews C, et al. American College of Sports Medicine roundtable on exercise guidelines for cancer survivors. Med Sci Sports Exerc. 2010;42(7):1409-26.

30. Servaes P, van der Werf S, Prins J, Verhagen S, Bleijenberg G. Fatigue in disease-free cancer patients compared with fatigue in patients with chronic fatigue syndrome. Support Care Cancer. 2001;9(1):11-7.

31. Stephenson R, Richardson B. Building an interprofessional curriculum framework for health: a paradigm for health function. $A d v$ Health Sci Educ Theory Pract. 2008;13(4):547-57.

32. Stewart AL, Mills KM, King AC, Haskell WL, Gillis D, Ritter PL. CHAMPS physical activity questionnaire for older adults: outcomes for interventions. Med Sci Sports Exerc. 2001;33(7):1126-41.

33. Tazaki M, Yamaguchi T, Yatsunami M, Nakane Y. Measuring functional health among the elderly: Development of the Japanese version of the World Health Organization Disability Assessment Schedule II. Int J Rehabil Res. 2014;37(1):48-53.

34. The WHOQOL Group. The World Health Organization Quality of Life assessment (WHOQOL): Position paper from the World Health Organization. Soc Sci Med. 1995;41(10):1403-9.

35. Tudor-Locke CE, Myers AM. Challenges and opportunities for measuring physical activity in sedentary adults. Sports Med. 2001; 31(2):91-100.

36. Vallance JK, Boyle T, Courneya KS, Lynch BM. Associations of objectively assessed physical activity and sedentary time with health-related quality of life among colon cancer survivors. Cancer. 2014;120(18):2919-26.

37. van der Hoeken D, Riet-van Hoof K, Hoek HW. Dutch WHO-DAS II: Questionnaire to assess disability. The Hague: WHO Collaborating Centre WHO-DAS; 2000. 18 p.
38. van Roekel EH, Bours MJL, de Brouwer CP, et al. The applicability of the International Classification of Functioning, Disability, and Health to study lifestyle and quality of life of colorectal cancer survivors. Cancer Epidemiol Biomarkers Prev. 2014;23(7):1394- 405.

39. Vercoulen JH, Hommes OR, Swanink CM, et al. The measurement of fatigue in patients with multiple sclerosis. A multidimensional comparison with patients with chronic fatigue syndrome and healthy subjects. Arch Neurol. 1996;53(7):642-9.

40. Vercoulen JH, Swanink CM, Fennis JF, Galama JM, van der Meer JW, Bleijenberg G. Dimensional assessment of chronic fatigue syndrome. J Psychosom Res. 1994;38(5):383-92.

41. Vodermaier A, Linden W, Siu C. Screening for emotional distress in cancer patients: a systematic review of assessment instruments. J Natl Cancer Inst. 2009;101(21):1464-88.

42. Wagenmakers R, van den Akker-Scheek I, Groothoff JW, et al. Reliability and validity of the short questionnaire to assess healthenhancing physical activity (SQUASH) in patients after total hip arthroplasty. BMC Musculoskelet Disord. 2008;9:141.

43. Wendel-Vos GC, Schuit AJ, Saris WH, Kromhout D. Reproducibility and relative validity of the short questionnaire to assess health-enhancing physical activity. J Clin Epidemiol. 2003;56(12): 1163-9.

44. World Health Organization. International Classification of Functioning, Disability and Health (ICF). Geneva: World Health Organization; 2001. 299 p.

45. World Health Organization. Measuring Health and Disability: Manual for WHO Disability Assessment Schedule (WHODAS 2.0). Geneva: World Health Organization; 2010. 152 p.

46. Zigmond AS, Snaith RP. The hospital anxiety and depression scale. Acta Psychiatr Scand. 1983;67(6):361-70. 